\title{
Assessment of the Absorption Characteristics of Tear Production Tests Under Different Environmental Conditions
}

\author{
ALI A. ABUSHARHA, Ph.D. \\ The Department of Optometry and Vision Sciences Vice Dean for Academic Affairs, College of Applied Medical Sciences, \\ King Saud University
}

\begin{abstract}
Background: Aqueous deficiency dry eye is considered one of the main categories of dry eye syndrome. Many techniques have been developed to assess tear production and monitor tear film turnover. Methods such as Schirmer test, phenol red thread (PRT) test, and tear function index (TFI), have been widely used to diagnose aqueous deficient dry eye. All these tests are based on the principle of absorption of the tear from the lacrimal sac and then measuring the wetting length of the paper strip or cotton thread. The wetting length can be affected by environmental factors, particularly relative humidity, that could exert a strong effect on the absorption mechanism of the strips or threads used to measure tear production.
\end{abstract}

Aim of the Work: The aim of this study was to investigate the effect of changing room relative humidity on the absorption properties of phenol red thread (PRT) and Schirmer strips, and their accuracy of measuring tear film production.

Methods: Twenty healthy subjects (40 eyes) were recruited for this study. Tear film production was assessed using PRTs and Schirmer strips in two different environmental conditions. Two visits were required to conduct this study. One visit was used to measure tear production in a room without installing a humidifier. The other visit was used to measure tear film production after the room was humidified using portable air humidifiers.

Result: Mean tear production measurements in nonhumidified room were $16.04,4.09$ and $16.12 \pm 9.10 \mathrm{~mm}$ using PRTs and Schirmer strips respectively. At high humidity visit, mean measurements was $20,8.03 \mathrm{~mm}$ and $19.35,8.35 \mathrm{~mm}$.

Conclusion: The physical properties of the examination strips and threads used for measuring tear quantity could be affected by environmental conditions. Eye care practitioners should be aware of the variation in tear production measurements that may result from external factors.

Key Words: Tear production - Schirmer test - Phenol red thread-Environmental conditions.

Correspondence to: Dr. Ali A. Abusharha, E-Mail: aabusharha@ksu.edu.sa

\section{Introduction}

AQUEOUS deficiency dry eye is considered one of the main categories of dry eye syndrome [1] Abnormalities in lacrimal gland function can affect tear film production and turnover [1]. Other influencing factors include hormonal changes; aging could also affect tear production [2]. Reduced tear secretion may lead to increased tear osmolarity and inflammatory events that may result in potential damage to the ocular surface [3]. Dry eye syndrome can lead to many symptoms, such as eye irritation, burning sensation, blurred vision, and red eye [4]

However, these symptoms can be controlled by using different lubricant formulations. These formulations work by replacing the tears and lubricating the ocular surface $[\mathbf{5 , 6 ]}$. Other approaches, such as punctal occlusion insertion and antiinflammatory therapy, have been proposed for the treatment of dry eye syndrome [7].

Numerous techniques have been developed to assess tear production and monitor tear film turnover [8]. Different methods, including Schirmer test, phenol red thread (PRT) test, and tear function index (TFI), have been widely used to diagnose aqueous deficient dry eye $[\mathbf{9 , 1 0}$. Further, observation of the disappearance of fluorescein dye from the tears using fluorophotometric techniques has been utilized to estimate tear film turnover [11].

The Schirmer test was developed by Schirmer in 1903 [12]. It utilizes minimally invasive test strips that are inserted into the inferior fornix in order to assess lacrimal gland secretory function [13]. Subsequently, tear production can be estimated by measuring the wetting length of the strip. Although, poor sensitivity and specificity of the Schirmer test have been reported, [14] it is consid- 
ered a useful diagnostic tool due its speed and ease of clinical application and low cost.

The use of a cotton thread with phenol red was suggested by Hamano for the assessment of tear film secretory function; $\mathrm{PRT}$ is a $\mathrm{pH}$-sensitive indicator which changes its color from yellow to red when it is inserted into the eye [15]. The use of PRT is less invasive compared with other techniques, such as Schirmer test and TFI, which result in less stimulation of reflex tearing. A wetting length of less than $10 \mathrm{~mm}$ in 15 seconds has been suggested as the cut-off value between normal and dry eye, with a sensitivity of $86 \%$ and specificity of $83 \%$ [16] . However, a previous study has suggested that PRT measures residual tear in the eye rather than tear production [17].

The effect of environmental factors on the parameters of tear film is well-documented $[\mathbf{1 8 , 1 9 ]}$. Significant changes in production, stability, and evaporation of the tear film have been observed with changes in relative humidity [20]. Moreover, environmental factors, particularly relative humidity, exert a strong effect on the absorption mechanism of the strips or threads used to measure tear production [21]. Previous studies have shown that water vapor absorption and moisture content of paper increase as relative humidity increases [21] Therefore, this alteration of tear production strips may influence the accuracy of measurement of tear volume.

The aim of this study was to investigate the effect of changing room relative humidity on the absorption properties of Schirmer strips and PRTs, and their accuracy of measuring tear film production.

\section{Patients and Methods}

Twenty normal healthy subjects (40 eyes) with no history of ocular disorders were recruited for this study (mean age $23.8 \pm 3.3$ years). The study was conducted in tear film physiology lab at king Saud university between January and March 2017. The informed written consent of all participants was obtained prior to conducting this study. All study procedures were approved by the Applied Medical Sciences Ethics Committee.

Tear film production was assessed using Schirmer strips and PRTs in two different environmental conditions. Both techniques use the principle of inserting the folded end into the lower fornix, for 15 seconds and 5 minutes for PRTs and Schirmer strips, respectively. Subsequently, the wetting length is measured to estimate the tear production.
As the purpose of this study was to assess the absorption properties of PRTs and Schirmer strips under different environmental conditions, two visits were required to conduct this study. One visit was used to measure tear production in a room without installing a humidifier. The other visit was used to measure tear film production after the room was humidified using two portable air humidifiers (LB 88 , Beurer dual action Humidifier $\mathrm{GmbH}$, NeuUlm, Germany). Visits were arranged in an alternating manner. The maximum room relative humidity achieved by the portable humidifier was $70 \%$, where the room humidity without humidification was $28 \pm 6 \%$. Room temperature was constant during both visits $\left(21 \pm 2^{\circ} \mathrm{C}\right)$.

The tear production test was performed immediately after subjects entered the examination room to minimize the effect of ocular surface adaptation to the environmental conditions. The PRT was applied first because of its less invasive characteristic compared with Schirmer strips. Fifteen minutes later, the Schirmer strip was then used to assess tear production of the subject. The subjects were instructed to close their eye during the duration of the test period.

All data were statically analyzed using PASW Statistics version 18 (IBM corporation, Somers, NY, USA). A test of normality was carried out first using a Kolmogorov-Smirnov test. Normally distributed data were compared using a Paired sample $t$-test. Data not normally distributed were compared using Friedman's test and a post-hoc Wilcoxon rank-sum test.

\section{Results}

Mean of tear production assessed using PRT and Schirmer test over ranged of relative humidity are shown in Figs. $(1,2)$. Mean tear production measurements in non-humidified room were $16.04 \pm 4.09$ and $16.12 \pm 9.10 \mathrm{~mm}$ using PRTs and Schirmer strips respectively (Table 1 ). At high humidity visit, mean measurements was $20 \pm$ $8.03 \mathrm{~mm}$ and $19.35 \pm 8.35 \mathrm{~mm}$ for PRTs and Schirmer strips respectively (Table 1). Paired statistical tests showed no statistical difference in tear production measurements between two visits $(p>0.05)$.

Table (1): A table showing the mean and standard deviation of tear production measured by Schirmer Test and phenol red thread.

\begin{tabular}{lcc}
\hline & $\begin{array}{c}\text { Schirmer Test } \\
(\mathrm{mm})\end{array}$ & $\begin{array}{c}\text { PRT } \\
(\mathrm{mm})\end{array}$ \\
\hline Humidified & $19.15 \pm 8.35$ & $20.46 \pm 8.03$ \\
Non-Humidified & $16.12 \pm 9.10$ & $16.04 \pm 4.09$ \\
\hline
\end{tabular}




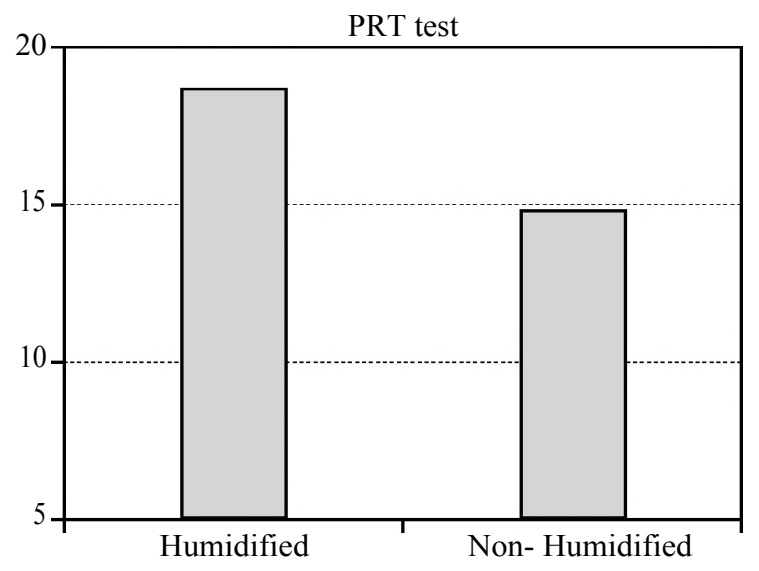

Fig. (1): Mean of tear production measurements evaluated using PRT in different relative humidity.

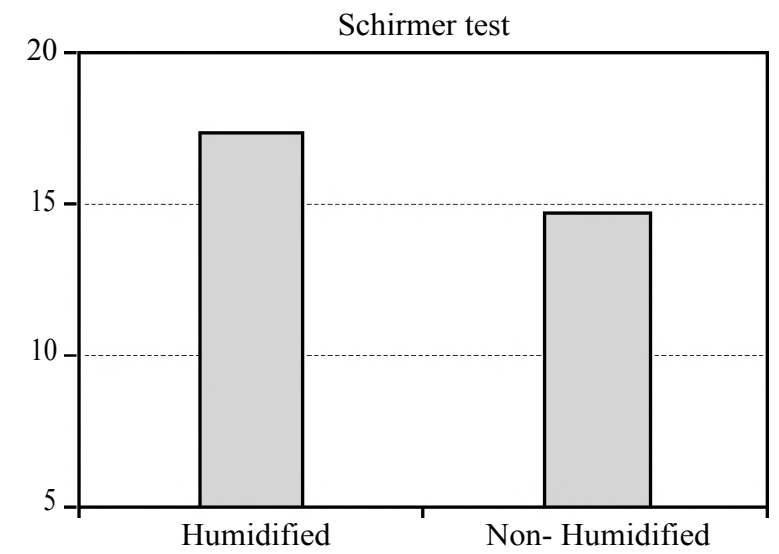

Fig. (2): Mean of tear production measurements evaluated using Schirmer test in different relative humidity.

\section{Discussion}

The main aim of this study was to assess the absorption properties of PRTs and Schirmer strips under different environmental conditions. In this study, investigations were conducted to assess the change in tear production measurements under different ambient conditions.

Turnover and production of tears is essential for maintaining a healthy ocular surface [22] . Reduction in tear film production can result in hyperosmolarity of the ocular surface, which leads to increase in the level of inflammatory mediators, and hence, damages the ocular surface [1]. Aqueous deficient dry eye is mainly caused by lacrimal gland dysfunction. Lacrimal gland dysfunction results from many factors, such as blockage of the sensory drive to the lacrimal gland or lacrimal duct obstruction [23]. Inflammatory infiltration of the lacrimal gland has been reported as one of the common causes of aqueous deficient dry eye [1]
Different methods have been developed for the purpose of measuring tear production and diagnosing aqueous deficient dry eye. Traditional diagnostic tools, such as Schirmer strips, PRT, and TFI, have been widely utilized to estimate production of tear film [14,24]. All these tests are based on the principle of absorption of the tear from the lacrimal sac and then measuring the wetting length of the paper strip or cotton thread.

However, the main concern regarding these techniques is their dependence on the absorption properties of the test strips and threads. Water content of the diagnostic tool before and during the test plays an important role on the estimation of tear production.

The moisture content of paper can change as a result of changing relative humidity $[21,25]$. Previous studies have shown that moisture content and diffusivity of paper increased significantly as the room humidity was increased [26,21] .

Moisture absorption under different amounts of humidity has been widely investigated. Studies have shown a significant effect on the physical properties of paper material due to humidity variation $[\mathbf{2 5 , 2 6 ]}$. Numerous equations have been fitted to moisture absorption in order to estimate the moisture content of paper under different environmental conditions [26].

In the current study, a difference in tear production measurements was found between the two visits. The measured tear quantity and wetting length of Schirmer strips and PRTs were higher when the room was humidified. Despite the fact that the differences were not statistically significant, it is clear from this finding that the physical properties and absorption characteristics of the tear production measurement tools was affected by the change in room humidity. Statistically significant results could be obtained in environments characterized by high fluctuation in relative humidity. A larger effect would be expected in cities on the east coast of Saudi Arabia, such as Dammam, where the humidity ranges between $20 \%$ and $90 \%$ throughout the year.

This phenomenon may not be overcome easily by clinical practitioners due to the variation in humidity in examination rooms. Therefore, it should be taken into consideration that variation in tear production measurements between visits to the clinic could be due to external factors related to environmental condition rather than the patient's tear film status. 
A more detailed study that includes a higher number of subjects is needed in order to better understand the mechanism by which the absorption properties of PRTs and the Schirmer are effected by ambient environmental conditions. In addition, further studies need to be done using techniques such as a controlled closed environmental chamber that give more accurate environmental parameters. Also, it has ability to produce a high range of fluctuation in relative humidity of the test environment.

\section{Conclusion:}

Environmental humidity fluctuates annually and geographically. This variation in humidity could affect the physical properties of the examination strips and threads used for measuring tear quantity. Eye care practitioners should be aware of the variation in tear production measurements that may result from external factors.

\section{References}

1- CRAIG J.P., NICHOLS K.K., AKPEK E.K., et al.: TFOS DEWS II definition and classification report. The Ocular Surface, 15: 276-83.

2- LEMP M.A.: Advances in understanding and managing dry eye disease. Am. J. Ophthalmol., 146: 350-6, 2008.

3- LIU H.X., BEGLEY C., CHEN M.H., et al.: A Link between Tear Instability and Hyperosmolarity in Dry Eye. Invest. Ophthalmol. Vis. Sci., 50: 3671-9.

4- VAN TILBORG M.M., MURPHY P.J. and EVANS K.S.: Impact of dry eye symptoms and daily activities in a modern office. Optom. Vis. Sci., 94: 688-93, 2017.

5- TSUBOTA K., NAKAMURA S., IMADA T., et al.: Method of improving lacrimal secretion for dry eye treatment using macqui berry extract. In: Google Patents, 2018.

6- ASBELL P., VINGRYS A.J., TAN J., et al.: Clinical Outcomes of Fixed Versus As-Needed Use of Artificial Tears in Dry Eye Disease: A 6-Week, Observer-Masked Phase 4 Clinical Trial. Invest. Ophthalmol. Vis. Sci., 59: 2275-80, 2017, 2018.

7- BUCKLEY R.: Assessment and management of dry eye disease. Eye, 32: 200, 2018.

8- JACOBI C. and MESSMER E.: Diagnosis of dry eye disease. Der Ophthalmologe: Zeitschrift der Deutschen Ophthalmologischen Gesellschaft, 2018.

9- MCCANN L.C., TOMLINSON A., PEARCE E.I., KHANAL S., KAY S.B. and FISHER AC.: A clinical Alternative to Fluorophotometry for Measuring Tear Production in the Diagnosis of Dry Eye. Cornea 29: 74550, 2010.

10- LI S., KIM Y.H., LI W., LIN M.C. and RADKE C.J. : Human Lacrimal Production Rates from Modified Schirmer-Tear. Test. Optom. Vis. Sci., 95: 343-8, 2018.

11- GARASZCZUK I.K., MONTES MICO R., ISKANDER D.R. and EXPÓSITO A.C.: The tear turnover and tear clearance tests-a review. Expert review of Medical Devices, 15: 219-29, 2018.

12- CHO P. and BROWN B.: Review of the tear break-up time and a closer look at the tear break-up time of Hong Kong Chinese. Optom. Vis. Sci., 70: 30-8, 1993.

13- KAYE S.B., SIMS G., WILLOUGHBY C., FIELD A.E., LONGMAN L. and BROWN M.C.: Modification of the tear function index and its use in the diagnosis of Sjogren's syndrome. Br. J. Ophthalmol., 85: 193-9, 2001.

14- TOMLINSON A., DOANE M.G. and MCFADYEN A.: Inputs and Outputs of the Lacrimal System: Review of Production and Evaporative Loss. Ocul. Surf., 7: 186-98, 2009.

15- HAMANO H., HORI M., HAMANO T., et al.: A new method for measuring tears. The CLAO journal : official publication of the Contact Lens Association of Ophthalmologists, Inc., 9: 281-9.

16- PATEL S., FARRELL J., BLADES K. and GRIERSON D.: The value of a phenol red impregnated thread for differentiating between the aqueous and non-aqueous deficient dry eye. Ophthalmic. Physiol. Opt., 18:471-6, 1998.

17- TOMLINSON A., BLADES K.J. and PEARCE E.I.: What does the phenol red thread test actually measure? Optom. Vis. Sci., 78: 142-6, 2001

18- GALOR A., KUMAR N., FEUER W. and LEE DJ.: Environmental Factors Affect the Risk of Dry Eye Syndrome in a United States Veteran Population. Ophthalmology, 121: 972-3.e1, 2014.

19- WOLKOFF P.: Ocular discomfort by environmental and personal risk factors altering the precorneal tear film. Toxicol. Lett., 199: 203-12, 2010.

20- ABUSHARHA A.A., PEARCE E.I.: The Effect of Low Humidity on the Human Tear Film. Cornea, 32: 429-34, 2012.

21- BANDYOPADHYAY A., RADHAKRISHNAN H., RAMARAO B. and CHATTERJEE S.: Moisture sorption response of paper subjected to ramp humidity changes: Modeling and experiments. Industrial \& Engineering Chemistry Research, 39: 219-26, 2000.

22- KHANAL S., TOMLINSON A. and DIAPER C.J.M.: Tear Physiology of Aqueous Deficiency and Evaporative Dry Eye. Optom. Vis. Sci., 86: 1235-40, 2009.

23- LEMP M.A., BAUDOUIN C., BAUM J., et al.: The definition and classification of dry eye disease: Report of the Definition and Classification Subcommittee of the international Dry Eye Work Shop Ocul. Surf., 5: 75-92, 2007.

24- LEMP M.A., BRON A.J., BAUDOUIN C., et al.: Tear Osmolarity in the Diagnosis and Management of Dry Eye Disease. Am. J. Ophthalmol., 151: 792-8, 2011.

25- RAMARAO B., MASSOQUETE A., LAVRYKOV S. and RAMASWAMY S.: Moisture diffusion inside paper materials in the hygroscopic range and characteristics of diffusivity parameters. Drying Technol., 21: 2007-56, 2003.

26- HASLACH H.W. : The moisture and rate-dependent mechanical properties of paper: A review. Mechanics of Time-dependent Materials, 4: 169-210, 2000. 


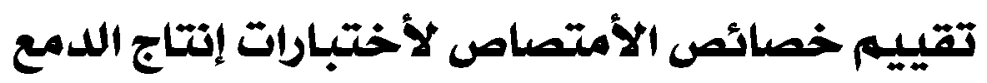

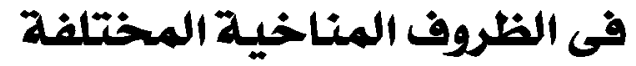

يمكن أن تتأثر الخواص الفيزيائية لشرائط وخيوط الفحص المستخدمة لقياس كمية الدمع بالعوامل البيئية. لذلك ينبغى أن يكون ممارسو رعائ العيون لى وعى بالأختلاف في قياسات إنتاج الدمع والتى قد تنتج عن عوامل خارجية متعلقة بنسبة الرطوية وكمية بخار الماء الموجود في غرفة الفحص.

الخلفية: يعتبر جفاف العين الناتج عن كفاية إنتاج الدمع من الغدة الدمعية أحد الأنفاع الأساسية لمتلازمة جفاف العين. و لتشخيص هذا

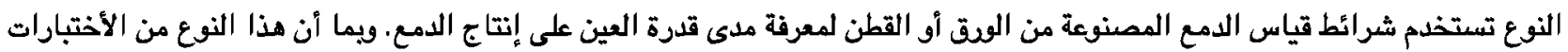

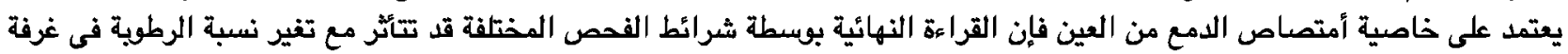

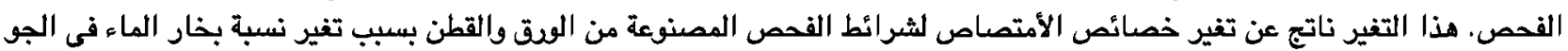
المحيط بها.

الهدف من البحث: إن الهدف من البحث هو معرفة مدى تأثير تغير الرطوبية النسبية فى الفرفة على خواص الأمتصاص لخيوط الفينول

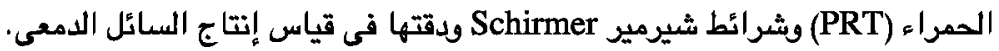

